\title{
Streptokinase Treatment Reverses Biofilm-Associated Antibiotic Resistance in Staphylococcus aureus
}

\author{
Nis Pedersen Jørgensen ${ }^{1,2}$, Natalia Zobek ${ }^{1}$, Cindy Dreier ${ }^{1}$, Jakob Haaber ${ }^{3}$, Hanne Ingmer ${ }^{3}$, \\ Ole Halfdan Larsen ${ }^{4}$ and Rikke L. Meyer ${ }^{1,5, *}$ \\ 1 Interdisciplinary Nanoscience Center, Aarhus University, 8000 Aarhus C, Denmark; nisjoerg@rm.dk (N.P.J.); \\ zobeknatalia@gmail.com (N.Z.); cd@inano.au.dk (C.D.) \\ 2 Department of Infectious Diseases, Aarhus University Hospital, 8200 Aarhus N, Denmark \\ 3 Department of Veterinary Disease Biology, University of Copenhagen, 1870 Frederiksberg C, Denmark; \\ jhaa@sund.ku.dk (J.H.); hi@sund.ku.dk (H.I.) \\ 4 Department of Clinical Biochemistry, Aarhus University Hospital, 8200 Aarhus N, Denmark; \\ ole.halfdan.larsen@clin.au.dk \\ 5 Department of Bioscience, Aarhus University, 8000 Aarhus C, Denmark \\ * Correspondence: rikke.meyer@inano.au.dk
}

Academic Editor: John E. Gustafson

Received: 7 July 2016; Accepted: 14 September 2016; Published: 20 September 2016

\begin{abstract}
Biofilms formed by Staphylococcus aureus is a serious complication to the use of medical implants. A central part of the pathogenesis relies on S. aureus' ability to adhere to host extracellular matrix proteins, which adsorb to medical implants and stimulate biofilm formation. Being coagulase positive, S. aureus furthermore induces formation of fibrin fibers from fibrinogen in the blood. Consequently, we hypothesized that fibrin is a key component of the extracellular matrix of S. aureus biofilms under in vivo conditions, and that the recalcitrance of biofilm infections can be overcome by combining antibiotic treatment with a fibrinolytic drug. We quantified S. aureus USA300 biofilms grown on peg-lids in brain heart infusion (BHI) broth with $0 \%-50 \%$ human plasma. Young $(2 \mathrm{~h})$ and mature $(24 \mathrm{~h}$ ) biofilms were then treated with streptokinase to determine if this lead to dispersal. Then, the minimal biofilm eradication concentration (MBEC) of $24 \mathrm{~h}$ old biofilms was measured for vancomycin and daptomycin alone or in combination with $10 \mu \mathrm{g} / \mathrm{mL}$ rifampicin in the presence or absence of streptokinase in the antibiotic treatment step. Finally, biofilms were visualized by confocal laser scanning microscopy. Addition of human plasma stimulated biofilm formation in BHI in a dose-dependent manner, and biofilms could be partially dispersed by streptokinase. The biofilms could be eradicated with physiologically relevant concentrations of streptokinase in combination with rifampicin and vancomycin or daptomycin, which are commonly used antibiotics for treatment of $S$. aureus infections. Fibronolytic drugs have been used to treat thromboembolic events for decades, and our findings suggest that their use against biofilm infections has the potential to improve the efficacy of antibiotics in treatment of $S$. aureus biofilm infections.
\end{abstract}

Keywords: USA300; biofilm; human plasma; fibrinolysis; MBEC

\section{Introduction}

A key aspect of pathogenesis by Staphylococcus aureus is the formation of biofilms [1] by interacting with mammalian extracellular matrix (ECM) molecules on ECM-covered surfaces in the body [2,3]. S. aureus possesses an array of cell wall-anchored proteins responsible for these specific receptor-ligand interactions, collectively called "microbial surface components recognizing adhesive matrix molecules" [2]. These include Clumping factor A and B and SdrE which bind to fibrinogen and complement factors [4-6], the fibronectin- and fibrinogen-binding proteins FnBPA and FnBPB [7-9], 
the fibronectin-binding proteins Ebh, the collagen-binding Collagen Adhesin (Cna) [10], and many other proteins for which the ligands are yet to be described [2]. In addition to these receptor-ligand interactions, a recent study also demonstrated that cell-surface proteins containing particular domains with internal thioester bonds could react with fibrinogen to form a covalent interaction, and that many pathogens, including S. aureus, contain cell surface proteins with similar domains [11].

S. aureus biofilm infections are often localized to bones, soft tissues, heart valves [12-14], or implants which are quickly covered with ECM molecules following implantation [15-17]. After adhesion to ECM molecules, S. aureus induces coagulation, which results in the formation of a three dimensional matrix of fibrin around the cells. S. aureus secretes two proteins that induce coagulation: coagulase and von Willebrand factor-binding protein. These proteins highjack the coagulation cascade by binding to prothrombin, which results in the formation of staphylothrombin that converts fibrinogen to fibrin. Conversely, S. aureus can also induce degradation of fibrin by secreting staphylokinase, which activates plasminogen to plasmin—a serine protease capable of fibrinolysis.

The addition of human plasma facilitates coagulation during growth of $S$. aureus in laboratory media and therefore greatly stimulates biofilm formation in vitro [18,19]. In vivo, the production of coagulase and the fibrin-binding Clumping factor A and FnBPs are reported to be particularly critical for biofilm formation [20]. Along with the reported lack of biofilm formation in staphylokinase-overexpressing strains [21], these findings testify to the key role of fibrin in the S. aureus biofilm matrix in vivo.

The formation of a fibrin matrix provides $S$. aureus with an ideal defense mechanism against immune cells [22,23], and S. aureus biofilms are also more recalcitrant to antibiotic therapy, both in vitro and in vivo [24-26]. The antibiotic dosage required for eradication of a mature $S$. aureus biofilms in vitro are in the range of 256-2048 mg/L for vancomycin, daptomycin, and other relevant anti-staphylococcal drugs, which far exceeds the concentration that can be achieved in vivo [25,27]. This recalcitrance to antibiotic treatment is due to a combination of several factors, including the reduced penetration and lower diffusion coefficient of many antibiotics in the biofilm, which has been demonstrated for S. aureus biofilms with, for example, vancomycin, oxacillin, and cefotaxime [28,29].

Due to the low efficacy of antimicrobials against cells within biofilms, a combined approach is gaining increasing interest, where the matrix of biofilms is targeted to disperse the biofilm while simultaneously applying antimicrobials. Enzymatic degradation of matrix polysaccharides or eDNA has been applied with varying success in vitro [30-32]. However, the knowledge that host-derived components, particularly fibrin, are more important components of the $S$. aureus biofilm matrix in vivo suggests these might be more efficacious targets.

Only a handful of studies have investigated this idea so far. Activation of plasminogen by fibrinolytic drugs is used to treat blood clots, and the same principle could be applied to dissolve the fibrin of S. aureus biofilms. Nemoto et al. were the first to demonstrate that $10,000 \mathrm{U} / \mathrm{mL}$ of the fibrinolytic drug Varidase (streptokinase) given concurrently with ofloxacin enhanced the efficacy of antibiotic treatment of in vitro grown S. aureus biofilms [33]. Recently, several studies have shown that prevention of fibrin formation leads to decreased biofilm formation and higher antibiotic susceptibility of in vivo grown S. aureus biofilms. This was shown by preventing S. aureus-mediated coagulation by adding a thrombin inhibitor to jugular vein catheters in mice [34], or by adding human plasminogen to a staphylokinase-overexpressing $S$. aureus strain, which led to fibrin dissolution as a result of staphylokinase-mediated activation of plasminogen [20]. Biofilm formation was also reduced by coating implant surfaces with the human tissue plasminogen activator (tPA), and the biofilms that did form were more susceptible to antibiotics [35]. These are encouraging results for the possibility of preventing biofilm formation to avoid acute infections on new implants. However, the treatment of biofilm infections that occur years after implantation is even more critical. Zapotoczna et al. [19] showed that $S$. aureus biofilms formed in vivo in a catheter inserted in the jugular vein in a rat model could be dispersed ex vivo by treating the biofilm with nattokinase. It is, however, not known if 
the same effect can be obtained in vivo, and which antibiotic concentration is needed to eradicate the biofilm.

The aim of this study was therefore to determine if S. aureus USA 300 biofilms could be eradicated by combining streptokinase with selected antibiotics at physiologically relevant concentrations. We grew $S$. aureus biofilms in a high throughput peg-lid biofilm assay and quantified the amount of biofilm after growth in brain heart infusion (BHI) amended with different concentrations of human plasma. We then determined the effect of streptokinase treatment on biofilm dispersal, and on the minimal biofilm eradication concentration (MBEC) of antibiotics provided as single drugs or in combinations. Finally, confocal laser scanning microscopy visualized the biofilm architecture and viability.

\section{Materials and Methods}

\subsection{Human Plasma Extraction}

Human plasma was generously provided by the Blood Bank, Aarhus University Hospital. Identification of the individual donors was not possible. Donors had signed a generalized consent form and since the blood was not to be used in studies involving screening for undiagnosed conditions, further ethical approval was not necessary. Blood from healthy donors was stabilized in $10 \mathrm{~mL}$ tubes (BD Vacutainer, Beckton Dickinson, Albertslund, Denmark) coated with EDTA (1.8 mg EDTA/mL blood). Plasma was separated from whole blood by centrifugation at $6000 \times g$ for $10 \mathrm{~min}$ at $5{ }^{\circ} \mathrm{C}$. Subsequently, plasma from more than 100 different donors was pooled to ensure reproducibility.

\subsection{Quantification of Human Plasma's Effect on Biofilm Formation}

S. aureus USA300 was stored in $50 \%$ glycerol at $-80{ }^{\circ} \mathrm{C}$. Prior to each experiment, $1 \mu \mathrm{L}$ was streaked on Tryptic Soy Agar (TSA) (Sigma-Aldrich, Copenhagen, Denmark) and incubated at $37{ }^{\circ} \mathrm{C}$ until colonies formed, and then stored at $5{ }^{\circ} \mathrm{C}$ for up to one month. A single colony was used to inoculate $10 \mathrm{~mL}$ 3.7\% Brain-Heart Infusion broth (BHI) (Sigma-Aldrich, Copenhagen, Denmark) in Erlenmeyer flasks and incubated at $37^{\circ} \mathrm{C}$ and subjected to $100 \mathrm{rpm}$ shaking for $16-18 \mathrm{~h}$. The overnight culture was then adjusted to $\mathrm{OD}_{600}=5.0$ in fresh BHI.

Biofilms were grown in a modified Calgary Biofilm Device protocol [36]. We used flat-bottom 96-well microtiter plates (NUNC 161093, Thermo Fisher Scientific, Hvidovre, Denmark) and matching peg-lids (NUNC-TSP 445497, Thermo Fisher Scientific). Each peg-lid was pre-conditioned by inserting it into a 96-well plate containing $180 \mu \mathrm{L} /$ well 3.7\% BHI enriched with 50\% human plasma for $30 \mathrm{~min}$ at $37^{\circ} \mathrm{C}$. Peg-lids were then transferred into a new microtiter plate containing $20 \mu \mathrm{L}$ of the overnight culture of S. aureus USA300 prepared as described above, and $180 \mu \mathrm{L}$ of BHI enriched with either $0 \%$, $5 \%, 10 \%, 25 \%$, or $50 \%$ plasma. After $2 \mathrm{~h}$ incubation at $37^{\circ} \mathrm{C}$, the peg-lids, now covered with a biofilm, were transferred back to the microtiter plates used for pre-conditioning and incubated for $24 \mathrm{~h}$ at $37^{\circ} \mathrm{C}$ to allow further growth and maturation of the biofilm. To simplify nomenclature, we will refer to the $2 \mathrm{~h}$ biofilm as "immature" and the $2+24 \mathrm{~h}$ as "mature" in the following sections.

The amount of biofilm was then quantified using the crystal violet assay as follows: Each peg-lid with biofilm was dried at $37{ }^{\circ} \mathrm{C}$ for 30-60 min and then transferred to a 96-well plate containing $200 \mu \mathrm{L} /$ well freshly prepared $0.5 \%$ crystal violet solution (Sigma-Aldrich) in demineralized water, and left to stain at room temperature for $10 \mathrm{~min}$. Excess stain was removed from the peg-lid by gently rinsing it three times by submersion in demineralized water. After rinsing, the lid was transferred to a new 96-well plate containing $200 \mu \mathrm{L} /$ well $96 \%$ ethanol. After $10 \mathrm{~min}$, the peg-lid was discarded, and the optical density of the crystal violet-stained ethanol solutions was measured at $585 \mathrm{~nm}$. This experiment was carried out with a minimum of 8 replicates.

\subsection{Biofilm Dispersal with Streptokinase}

The peg-lid with S. aureus USA300 biofilm (prepared as described above using BHI with 50\% plasma) was transferred to a 96-well plate containing $200 \mu \mathrm{L} /$ well of freshly prepared (up to $5 \mathrm{~min}$ 
in advance) streptokinase (Sigma-Aldrich) in BHI and incubated for $1 \mathrm{~h}$ at $37^{\circ} \mathrm{C}$. The amount of the biofilm was then quantified using the crystal violet assay as described above. Treatment of immature biofilms was performed with $0,50,100$, and $150 \mathrm{U} / \mathrm{mL}$ streptokinase, while mature biofilms were treated with $500 \mathrm{U} / \mathrm{mL}$ streptokinase in BHI. This experiment was performed with a minimum of three replicates.

\subsection{MBEC of Antibiotics Combined with Streptokinase}

Mature biofilms were prepared as described above using BHI with 50\% plasma or tryptic soy broth (TSB) (Fluka Analytical). Antibiotics were dissolved into BHI, and serially diluted (two-fold in each step) in a 96-well plate, such that concentration ranges were 0-2048 $\mu \mathrm{g} / \mathrm{mL}$ for vancomycin (Sigma-Aldrich) and daptomycin (Cubicin, Novartis, Denmark). The concentration of rifampicin (Eramfat, Riemser Pharma GmbH, Greifswald, Germany) was, however, kept constant at $10 \mu \mathrm{g} / \mathrm{mL}$. Peg-lids with mature biofilms were transferred to the plate containing BHI with antibiotics, or antibiotics with $500 \mathrm{U} / \mathrm{mL}$ streptokinase (Sigma-Aldrich), and incubated for $24 \mathrm{~h}$ at $37^{\circ} \mathrm{C}$. The combination of antibiotics tested were: vancomycin alone, vancomycin with rifampicin, daptomycin alone, and daptomycin with rifampicin.

After antibiotic exposure, biofilms were rinsed by gently submerging the lid in a 96-well plate containing BHI three times and were then transferred to a "recovery plate" containing $500 \mathrm{U} / \mathrm{mL}$ streptokinase solution in BHI, and incubated for $24 \mathrm{~h}$ at $37^{\circ} \mathrm{C}$. The absence of viable cells among the bacteria detached from the biofilm during incubation with antibiotics and streptokinase was confirmed by spotting $10 \mu \mathrm{L}$ to a fresh agar plate and incubating overnight at $37^{\circ} \mathrm{C}$. Bacteria-free pegs were used as blanks, and pegs with biofilms that had not been treated with antibiotics were used as growth controls. After the incubation, peg-lids were discarded and planktonic growth was assessed in the wells by transferring $5 \mu \mathrm{L}$ from wells without visible growth to TSA and incubating for $24 \mathrm{~h} 37^{\circ} \mathrm{C}$ before assessing the presence of colonies. The experiment was performed with a minimum of eight replicates, and the MBEC value was determined as the antibiotic concentration resulting in the absence of viable cells in the recovery plate in at least five out of eight replicates.

It should be noted that streptokinase is usually not included in the recovery plates in standard MBEC protocols. However, in control experiments we found no growth in the recovery plates, even in the absence of antibiotics. Hence the $S$. aureus cells were so firmly attached in the biofilm that no planktonic growth resulted from transferring the biofilm to fresh BHI. With streptokinase in the recovery media, all controls were positive for planktonic growth (see results section).

\subsection{Confocal Laser Scanning Microscopy (CLSM)}

Microtiter plates for microscopy (Product \# 89621, Ibidi, Munich, Germany) were pre-conditioned in $180 \mu \mathrm{L}$ modified BHI-plasma medium containing $78 \mu \mathrm{L}$ plasma, $90 \mu \mathrm{L}$ BHI, and $12 \mu \mathrm{L}$ Alexa Fluor ${ }^{\circledR}$ 647-conjugated fibrinogen (Thermo Fisher Scientific) in sodium bicarbonate, pH 8.3. The resulting concentration of Alexa Fluor-conjugated fibrinogen was $200 \mu \mathrm{g} / \mathrm{mL}$, which corresponds to approximately $20 \%$ of the total fibrinogen expected to be present in the media. The plates were incubated for $30 \mathrm{~min}$ at $37^{\circ} \mathrm{C}$ before the addition of $20 \mu \mathrm{L}$ of overnight culture (adjusted to $\mathrm{OD}_{600}=5$ ) was added to each well (final $\mathrm{OD}_{600}=0.50$, final volume $=200 \mu \mathrm{L} /$ well) and incubated for $2 \mathrm{~h}$ at $37^{\circ} \mathrm{C}$. The medium was then gently removed by aspiration and replaced with $300 \mu \mathrm{L}$ of the modified BHI-plasma medium. The plate was then incubated for $24 \mathrm{~h}$ at $37^{\circ} \mathrm{C}$ to generate mature biofilms. The biofilms were then incubated for another $24 \mathrm{~h}$ at $37^{\circ} \mathrm{C}$ in fresh media (modified BHI-plasma medium), or media amended with $4 \mu \mathrm{g} / \mathrm{mL}$ vancomycin and $10 \mu \mathrm{g} / \mathrm{mL}$ rifampicin, or media amended with $500 \mathrm{U} / \mathrm{ml}$ streptokinase in addition to the antibiotics.

CLSM imaging was done with a Zeiss LSM700 confocal laser scanning microscope (Zeiss, Jena, Germany). The medium was removed, and each well was gently rinsed five times in $300 \mu \mathrm{L}$ sterile phosphate buffered saline (PBS) before adding $150 \mu \mathrm{L}$ PBS containing $10 \mu \mathrm{M}$ of the membrane-permeant DNA-binding stain SYTO 41 (Thermo Fisher Scientific) for live-cell imaging, 
and $2 \mu \mathrm{M}$ of the membrane-impermeant DNA-binding stain TOTO ${ }^{\circledR}-1$ (Thermo Fisher Scientific) for dead cell imaging. The biofilms were incubated at room temperature for $45-60$ min with the staining solution before imaging. SYTO 41 and Alexa Fluor ${ }^{\circledR} 647$ were captured in one track with excitation by the $405 \mathrm{~nm}$ and $635 \mathrm{~nm}$ lasers and splitting the emission to the two photomultipliers at $600 \mathrm{~nm}$, and TOTO $^{\circledR}-1$ was then captured by excitation with the $488 \mathrm{~nm}$ laser in a second track.

\subsection{Statistics}

Statistical tests were done using the GraphPad Prism 5.0f (Graphpad Software, La Jolla, CA, USA). The data was plotted to assess normal distribution, and since the data follow a normal distribution, all tests were done using parametric testing (Student's $t$-test).

First-order and zero order equations were fitted to the data from crystal violet staining of biofilms to determine the dose-response effect of adding human plasma to BHI, and of treating pre-formed biofilms with increasing concentrations of streptokinase.

\section{Results}

\subsection{Human Plasma Promotes Formation of Biofilms That Can Be Dispersed by Streptokinase Treatment}

S. aureus USA300 formed very little biofilm in BHI, but the addition of increasing concentrations of plasma led to a dose-dependent increase in biofilm formation (Figure 1). The amount of biofilm formed increased linearly $\left(R^{2}=0.96\right)$ at plasma concentrations up to $25 \%$ and then leveled off, indicating that the availability of plasma proteins was the limiting factor for biofilm formation at plasma concentrations below $25 \%$.

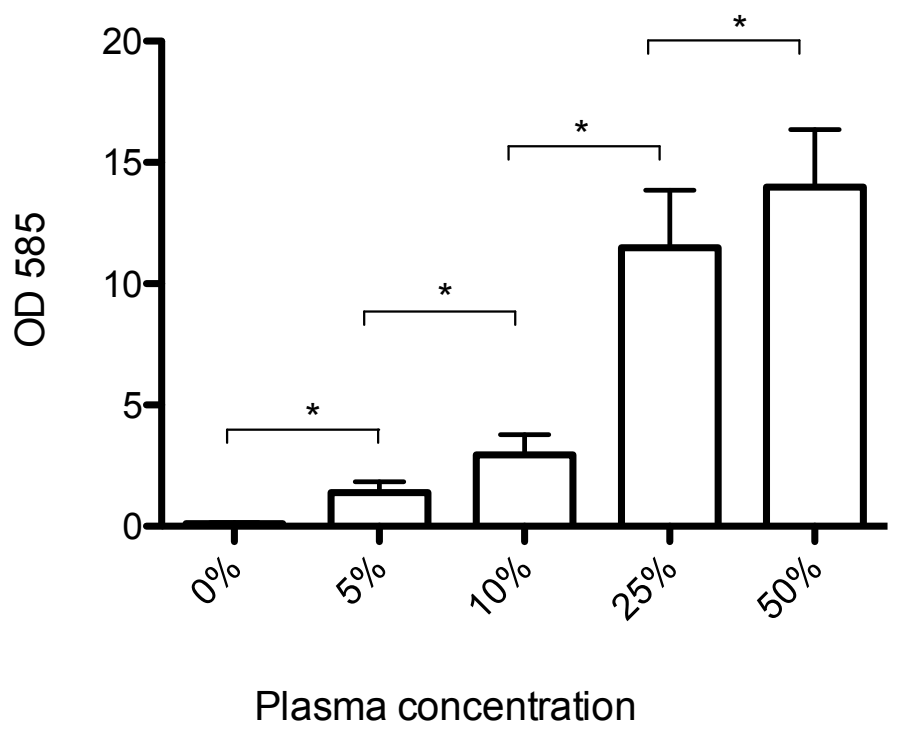

Figure 1. Mean biofilm biomass ( $\pm \mathrm{SD}, n=8)$, measured by crystal violet staining. USA300 formed very little biofilm in pure brain heart infusion (BHI), but the addition of human plasma led to increased biofilm formation in a dose-dependent manner. ${ }^{*}$ significantly different $(p<0.001)$.

Immature ( $2 \mathrm{~h}$ old ) biofilms could be partially dispersed by $1 \mathrm{~h}$ streptokinase treatment (Figure $2 \mathrm{~A}$ ). The amount of biofilm decreased in a dose-dependent manner after treatment with 50, 100, or 150 U/mL streptokinase $(p<0.05)$. Mature $(24 \mathrm{~h}$ old $)$ biofilms could also be dispersed, but required higher streptokinase concentrations. Treatment with $500 \mathrm{U} / \mathrm{mL}$ lead to a 22-fold reduction of biomass from 25.8 to 1.2 (Figure $2 \mathrm{~B}$ ). 
A

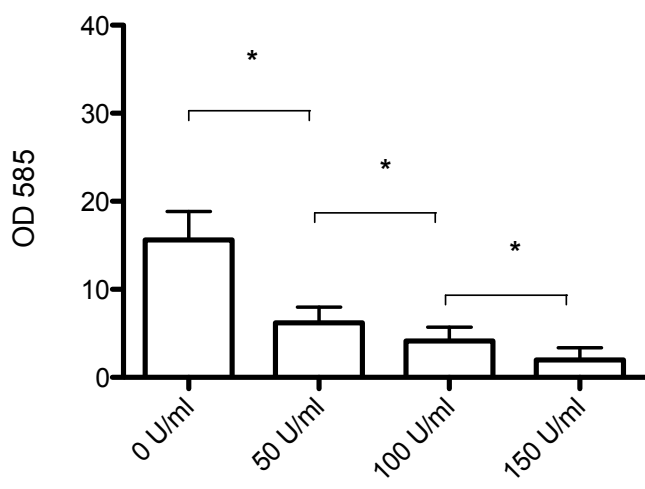

Streptokinase concentration
B

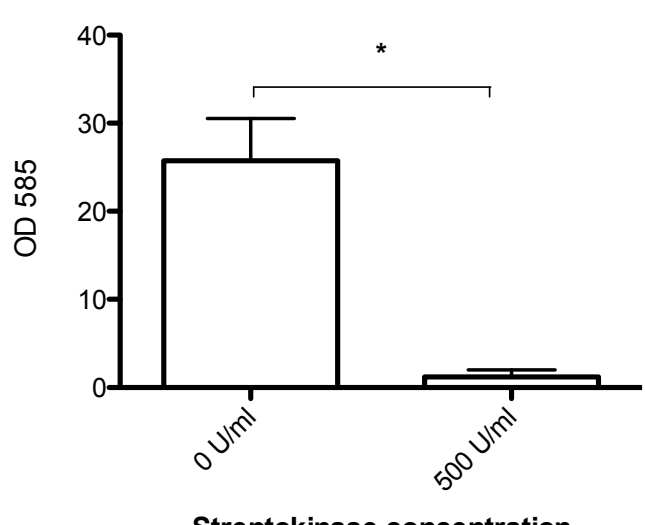

Streptokinase concentration

Figure 2. Mean biofilm biomass ( $\pm \mathrm{SD}, n=8$ ), measured by crystal violet staining after incubation of $2 \mathrm{~h}$ old (A) and $24 \mathrm{~h}$ old (B) biofilms with streptokinase for $24 \mathrm{~h}$. Increasing concentrations of streptokinase resulted in a dose dependent decrease in biomass. A single high dose was applied to $24 \mathrm{~h}$ old biofilms, resulting in almost complete biofilm dispersal. * significantly different $(p<0.001)$.

\subsection{Streptokinase Treatment Lowers the MBEC to Clinically Relevant Levels}

The addition of streptokinase during antibiotic treatment dramatically increased the susceptibility of biofilms to antibiotics, resulting in lower MBEC values (Table 1). The most pronounced effect was observed when streptokinase was applied together with a combination of rifampicin and either vancomycin or daptomycin. The combination of streptokinase and two antibiotics lowered the MBEC to a level that can safely be obtained in vivo (Table 1).

Table 1. Minimal biofilm eradication concentration (MBEC) against biofilms of S. aureus USA300 grown for $24 \mathrm{~h}$ in $\mathrm{BHI}$ with $50 \%$ plasma and incubated with antibiotics in the presence or absence of streptokinase. Rifampicin was added as a fixed dosage of $10 \mathrm{mg} / \mathrm{L}$.

\begin{tabular}{ccc}
\hline Antibiotic & MBEC (-Streptokinase) (mg/L) & MBEC (+Streptokinase) (mg/L) \\
\hline Daptomycin & 1024 & 1024 \\
Daptomycin + rifampicin & 64 & $<4$ \\
Vancomycin & 128 & 64 \\
Vancomycin + rifampicin & 64 & 4 \\
\hline
\end{tabular}

We hypothesized that fibrin was a major part of the biofilm matrix, and that the effect of streptokinase was due to fibrinolysis. We therefore visualized the biofilm architecture, including the fibrin component. S. aureus USA300 biofilms were grown for $24 \mathrm{~h}$ in BHI supplemented with human plasma and Alexa Fluor ${ }^{\circledR}$ conjugated fibrinogen before transferring and incubating the biofilms for an additional $24 \mathrm{~h}$ in either fresh media, or media supplemented with antibiotics, streptokinase, or both. CLSM imaging showed biofilms consisting of aggregates of cells with fibrin fibers extending more than $20 \mu \mathrm{m}$ from the cell surface (Figure 3A). The addition of $4 \mathrm{mg} / \mathrm{L}$ vancomycin and $10 \mathrm{mg} / \mathrm{L}$ rifampicin did not result in visible losses of biomass or viable cells (Figure 3B), but the combination of antibiotics with streptokinase almost completely removed the fibrin and eliminated the biofilm (Figure 3C).

To test if a secondary non-fibrinolytic effect of streptokinase was at play, we grew biofilms in tryptic soy broth in the absence of human plasma and performed MBEC assays with and without streptokinase. These biofilms were deficient of fibrin and other human ECM proteins, and we confirmed that streptokinase had no effect on the MBEC values (Table 2). 


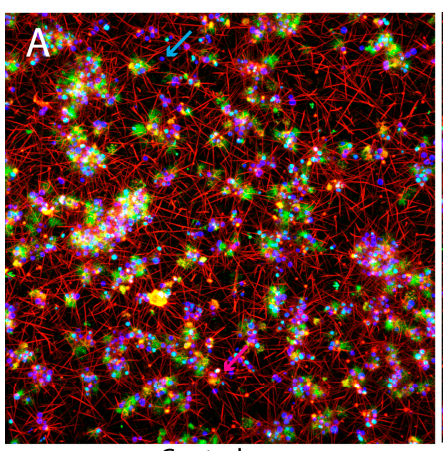

Control

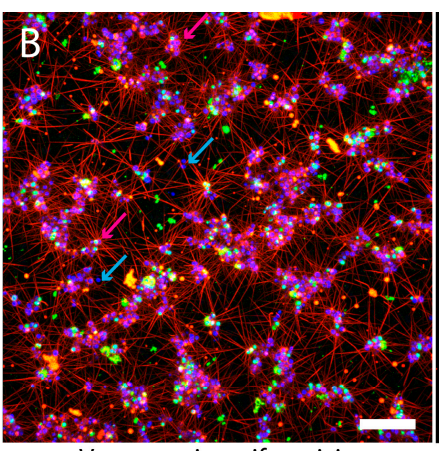

Vancomycin + rifampicin

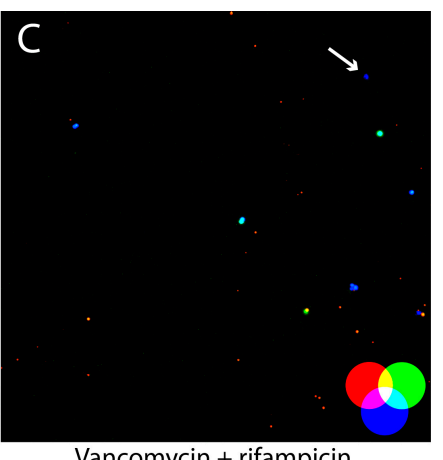

Vancomycin + rifampicin

+ streptokinase

Figure 3. Confocal Laser Scanning Microscopy (CLSM) imaging of USA300 biofilms grown in BHI with plasma and Alexa Fluor conjugated fibrinogen. After $24 \mathrm{~h}$ growth, biofilms were incubated for $24 \mathrm{~h}$ in media (A), or media amended with vancomycin $(4 \mathrm{mg} / \mathrm{L})$ and rifampicin $(10 \mathrm{mg} / \mathrm{L})(\mathbf{B})$, or media amended with vancomycin $(4 \mathrm{mg} / \mathrm{L})$ and rifampicin $(10 \mathrm{mg} / \mathrm{L})$ and streptokinase $(500 \mathrm{U} / \mathrm{mL})$ (C). Alexa Fluor conjugated fibrinogen appear red, viable cells stained by SYTO 41 appear blue, and dead cells stained by TOTO ${ }^{\circledR}-1$ appear green, cyan, and yellow because some of these cells also bound fibrinogen and SYTO 41. Blue arrows indicate cells that did not appear to bind fibrinogen, and pink arrows indicate cells that bound fibrinogen and appeared to cause coagulation of fibrinogen to fibrin fibers. Combination of antibiotics with streptokinase resulted in almost complete eradication of the biofilm. A single viable cell that did not bind $\mathrm{TOTO}^{\circledR}-1$ is indicated by the arrow. Scale bar $=20 \mu \mathrm{m}$.

Table 2. MBEC against biofilms of S. aureus USA 300 grown for $24 \mathrm{~h}$ in tryptic soy broth (TSB) and incubated with antibiotics in the presence or absence of streptokinase. Rifampicin was added at a fixed dosage of $10 \mathrm{mg} / \mathrm{L}$.

\begin{tabular}{ccc}
\hline Antibiotic & MBEC $(+$ Streptokinase) $(\mathrm{mg} / \mathrm{L})$ & MBEC $(-$ Streptokinase $)(\mathrm{mg} / \mathrm{L})$ \\
\hline Daptomycin + rifampicin & $>1024$ & $>1024$ \\
Vancomycin + rifampicin & $>1024$ & $>1024$ \\
\hline
\end{tabular}

\section{Discussion}

This study confirms that host-derived proteins are an integral part of the S. aureus USA300 biofilm matrix, and that fibrin provides a target for therapies that can potentiate the efficacy of conventional antibiotics.

The addition of plasma to BHI stimulated biofilm formation immediately, and the large amount of biofilm formed after the $2 \mathrm{~h}$ incubation period stresses that most of the biofilm was formed by the aggregation of cells and coagulation of fibrin, rather than by growth. As expected, the biofilms were rich in fibrin (Figure 3A,B), which extended as long fibers from the cell surface. Some cells, but not all, were also coated with fluorescent fibrinogen that did not appear to take a fibrillar form (Figure 3, blue and pink arrows). This cell to cell variation probably illustrates the variability in expression of fibrinogen binding proteins, such as FnBPs, clumping factor, and SdrE. It is also interesting to note that some of the dead cells, which were recognized by their ability to bind the membrane-impermeable stain TOTO $^{\circledR}-1$ (green), also appeared to be a source of fibrin production. Many of these cells appear yellow, as they also bind fibrinogen (red). This observation implies that dead cells may still be a source of coagulase, and that the remains of these cells bind to fibrinogen and fibrin, and thereby become integrated in the biofilm matrix.

Streptokinase only dispersed biofilms grown in BHI with plasma (Tables 1 and 2), and microscopy confirmed that fibrinolysis was responsible for this effect, as fibrin was completely removed from the biofilm after the addition of streptokinase (Figure 3). Streptokinase works by activating plasminogen to plasmin by proteolysis, and the fibrinolytic effect is therefore dependent on the presence of 
plasminogen. The treatment of biofilms with antibiotics and streptokinase was performed in BHI without plasma, and the available plasminogen must therefore be bound in the biofilm and transferred from the previous incubation in BHI with $50 \%$ plasma. Plasminogen can be bound to $S$. aureus cells by several mechanisms. Pietrocola et al. recently showed that FnBPB is responsible for binding the bulk of plasminogen bound in the $S$. aureus biofilm matrix [37]. Furthermore, the manganese transport protein $C$ is also capable of binding a range of human extracellular matrix and coagulation cascade proteins, including plasminogen [38]. This could explain why a sufficient amount of plasminogen was present to induce fibrinolysis in the biofilm upon activation by streptokinase in BHI. The dose-dependent response to increasing streptokinase concentrations even indicates that streptokinase and not plasminogen was the limiting factor for the biofilm dispersal.

The antibiotic susceptibility of the biofilms appeared to be strongly affected by the composition of the extracellular matrix. MBEC for vancomycin or daptomycin when combined with $10 \mathrm{mg} / \mathrm{L}$ rifampicin were only $64 \mathrm{mg} / \mathrm{L}$ for biofilms grown in BHI with $50 \%$ plasma, but exceeded the $1024 \mathrm{mg} / \mathrm{L}$ upper detection limit of the assay when biofilms were grown in TSB. This difference suggests that the MBEC for biofilms in vivo may not be as high as predicted by measurements made in standard laboratory media.

EDTA-stabilized plasma was chosen over heparin-stabilized plasma because previous studies have shown that heparin can induce biofilm formation by S. aureus [39]. However, EDTA can also induce adverse effects due to its toxicity. We used EDTA-stabilized plasma with a final EDTA concentration of $0.9 \mathrm{mg} / \mathrm{mL}$ in media with $50 \%$ plasma, but the concentration of free EDTA was likely much lower, as EDTA would be bound to components in the plasma. We confirmed that EDTA did not inhibit biofilm growth of S. aureus USA300, and the concentration of free EDTA must therefore have been below the MBC for this strain. Previous studies found a synergistic effect between antibiotics and EDTA against $S$. aureus biofilms, but these results were obtained at $30 \mathrm{mg} / \mathrm{mL}$ EDTA [40,41]. We therefore argue that the theoretical maximum of $0.9 \mathrm{mg} / \mathrm{mL}$ EDTA in our study was unlikely to have affected our results.

A natural limitation of our study is the ex vivo conditions, which raises the question of whether one would expect to obtain a similar effect of streptokinase in vivo, because the effect may depend on the biofilm thickness and architecture. Bjarnsholt et al. demonstrated that in vivo biofilms are generally thinner than in vitro grown biofilms, and often contains only a few cell layers [42]. Our in vitro grown biofilms were very thick and easily visible to the naked eye, and would therefore expect that the dose of streptokinase used in our experiment would also be effective on in vivo grown biofilms. We were able to fully disperse the biofilms (Figures 1 and 3) with a dosage of streptokinase that is many times lower than the dosages used to treat patients with thromboembolic events. Hence, even if the dosage used here is insufficient for dispersing in vivo grown biofilms, there is ample room for maneuvering when adapting this approach to in vivo treatment.

An important question is also whether our observations apply generally to S. aureus, as the matrix composition can vary from between strains, and the fibrin production is a balance between coagulase activity and staphylokinase activity. In particular, the methicillin-resistant S. aureus used in this study is known to rely more on proteins and less on polysaccharides compared to methicillin-sensitive S. aureus [43]. However, several recent studies have confirmed the important role of fibrin for methicillin-sensitive S. aureus biofilms in vivo [20,34], and that ex vivo treatment with fibrinolytic drugs can disperse biofilms that are formed on implant surfaces in vivo [19].

To the best of our knowledge, our study demonstrates for first time that a drug combination leads to eradication of mature biofilms at antibiotic concentrations that are achievable in patients. Nemoto et al. demonstrated that streptokinase treatment in combination with ofloxacin reduced the number of viable bacteria in S. aureus biofilms to less than $10 \%$ of tests with antibiotics alone [33]. However, this reduction was only achieved with a streptokinase dosage of $10,000 \mathrm{U} / \mathrm{mL}$ and an ofloxacin concentration of $128 \mathrm{mg} / \mathrm{L}$. While streptokinase can be administered at those concentrations, the ofloxacin concentration far exceeds what is clinically possible [44]. Even at this high concentration, biofilm eradication was not observed. 
We therefore hypothesized that the successful non-invasive eradication of S. aureus biofilms could be achieved at physiologically relevant antibiotic concentrations if fibrinolytic drugs were combined with the most effective combination of antibiotics. Indeed, we found no effect of streptokinase on the MBEC for daptomycin, and only a 50\% decrease of the MBEC for vancomycin when used as single drugs. It was only when combining one of the antibiotics with rifampicin that streptokinase treatment resulted in a dramatic decrease in the MBEC to clinically achievable levels. The maximum recommended dose of daptomycin is $10 \mathrm{mg} / \mathrm{kg}$, which results in a total in vivo concentration of approximately 10-100 mg/L [45]. Current clinical guidelines recommend a trough concentration of vancomycin of between $15-20 \mathrm{mg} / \mathrm{L}$ to avoid adverse events [46,47]. By combining a multi-drug treatment, we show here that biofilm eradication could be achieved at $4 \mathrm{mg} / \mathrm{L}$ daptomycin or vancomycin. As this concentration is easily achievable in vivo, our study provides an encouraging lead for further investigation of using this drug combination to treat biofilm infections.

Our study demonstrated that good in vitro models are essential for investigating the role of targeting the biofilm matrix to treat biofilm infections. We therefore stress the importance of host-derived proteins for the structure and properties of the biofilm matrix, and propose that human plasma is included as standard when growing Staphylococcus biofilms in vitro. If our findings are to be applied to the treatment of biofilms in vivo, the use of fibronolytic drugs in conjunction with antibiotics could improve treatment outcome for $S$. aureus biofilm infections. Prosthetic valve endocarditis caused by $S$. aureus has a one-year mortality rate of $50 \%$ and even with surgery performed, re-infection rate is about $6 \%-15 \%[48,49]$. The need to improve the efficacy of antibiotic treatment is therefore critical, and this study provides an important first step towards this goal.

\section{Conclusions}

In this study we demonstrated that adding human plasma to BHI increased biofilm formation by S. aureus USA300. Mature S. aureus biofilms could be eradicated with clinically relevant concentrations of daptomycin with rifampicin and vancomycin with rifampicin when treatment was concurrent with clinically relevant dosages of streptokinase.

Acknowledgments: We thank the Sapere Aude programme of the Danish Council for Independent Research (Grant No. 0602-02130B) for financial support. Also, a special thanks to the Blood Bank, Aarhus University Hospital for the donation of human plasma.

Author Contributions: The study was designed: N.P.J., R.L.M., O.H.L., J.H., and H.I. Laboratory work was conducted by N.Z. and C.D. Data analysis was performed by N.P.J. and R.L.M. Manuscript was written by N.P.J. and R.L.M.

Conflicts of Interest: The authors have no conflict of interest to declare.

\section{References}

1. Resch, A.; Leicht, S.; Saric, M.; Pasztor, L.; Jakob, A.; Gotz, F.; Nordheim, A. Comparative proteome analysis of Staphylococcus aureus biofilm and planktonic cells and correlation with transcriptome profiling. Proteomics 2006, 6, 1867-1877. [CrossRef] [PubMed]

2. Foster, T.J.; Geoghegan, J.A.; Ganesh, V.K.; Hook, M. Adhesion, invasion and evasion: The many functions of the surface proteins of Staphylococcus aureus. Nat. Rev. Microbiol. 2014, 12, 49-62. [CrossRef] [PubMed]

3. Otto, M. Staphylococcal infections: Mechanisms of biofilm maturation and detachment as critical determinants of pathogenicity. Annu. Rev. Med. 2013, 64, 175-188. [CrossRef] [PubMed]

4. Deivanayagam, C.C.; Wann, E.R.; Chen, W.; Carson, M.; Rajashankar, K.R.; Hook, M.; Narayana, S.V. A novel variant of the immunoglobulin fold in surface adhesins of Staphylococcus aureus: Crystal structure of the fibrinogen-binding mscramm, clumping factor a. EMBO J. 2002, 21, 6660-6672. [CrossRef] [PubMed]

5. Ganesh, V.K.; Barbu, E.M.; Deivanayagam, C.C.; Le, B.; Anderson, A.S.; Matsuka, Y.V.; Lin, S.L.; Foster, T.J.; Narayana, S.V.; Hook, M. Structural and biochemical characterization of Staphylococcus aureus clumping factor B/ligand interactions. J. Biol. Chem. 2011, 286, 25963-25972. [CrossRef] [PubMed] 
6. O’Brien, L.; Kerrigan, S.W.; Kaw, G.; Hogan, M.; Penades, J.; Litt, D.; Fitzgerald, D.J.; Foster, T.J.; Cox, D. Multiple mechanisms for the activation of human platelet aggregation by Staphylococcus aureus: Roles for the clumping factors CLFA and CLFB, the serine-aspartate repeat protein sdre and protein A. Mol. Microbiol. 2002, 44, 1033-1044. [CrossRef] [PubMed]

7. Keane, F.M.; Loughman, A.; Valtulina, V.; Brennan, M.; Speziale, P.; Foster, T.J. Fibrinogen and elastin bind to the same region within the a domain of fibronectin binding protein A, an mscramm of Staphylococcus aureus. Mol. Microbiol. 2007, 63, 711-723. [CrossRef] [PubMed]

8. Sinha, B.; Francois, P.; Que, Y.A.; Hussain, M.; Heilmann, C.; Moreillon, P.; Lew, D.; Krause, K.H.; Peters, G.; Herrmann, M. Heterologously expressed Staphylococcus aureus fibronectin-binding proteins are sufficient for invasion of host cells. Infect. Immun. 2000, 68, 6871-6878. [CrossRef] [PubMed]

9. Clarke, S.R.; Harris, L.G.; Richards, R.G.; Foster, S.J. Analysis of ebh, a 1.1-megadalton cell wall-associated fibronectin-binding protein of Staphylococcus aureus. Infect. Immun. 2002, 70, 6680-6687. [CrossRef] [PubMed]

10. Zong, Y.; Xu, Y.; Liang, X.; Keene, D.R.; Hook, A.; Gurusiddappa, S.; Hook, M.; Narayana, S.V. A 'collagen hug' model for Staphylococcus aureus cna binding to collagen. EMBO J. 2005, 24, 4224-4236. [CrossRef] [PubMed]

11. Walden, M.; Edwards, J.M.; Dziewulska, A.M.; Bergmann, R.; Saalbach, G.; Kan, S.Y.; Miller, O.K.; Weckener, M.; Jackson, R.J.; Shirran, S.L.; et al. An internal thioester in a pathogen surface protein mediates covalent host binding. Elife 2015, 4, e06638. [CrossRef] [PubMed]

12. Brady, R.A.; Leid, J.G.; Calhoun, J.H.; Costerton, J.W.; Shirtliff, M.E. Osteomyelitis and the role of biofilms in chronic infection. FEMS Immunol. Med. Microbiol. 2008, 52, 13-22. [CrossRef] [PubMed]

13. Archer, N.K.; Mazaitis, M.J.; Costerton, J.W.; Leid, J.G.; Powers, M.E.; Shirtliff, M.E. Staphylococcus aureus biofilms: Properties, regulation, and roles in human disease. Virulence 2011, 2, 445-459. [CrossRef] [PubMed]

14. Lister, J.L.; Horswill, A.R. Staphylococcus aureus biofilms: Recent developments in biofilm dispersal. Front. Cell. Infect. Microbiol. 2014, 4, 178. [CrossRef] [PubMed]

15. Gristina, A.G. Biomaterial-centered infection: Microbial adhesion versus tissue integration. Science 1987, 237, 1588-1595. [CrossRef] [PubMed]

16. Montanaro, L.; Speziale, P.; Campoccia, D.; Ravaioli, S.; Cangini, I.; Pietrocola, G.; Giannini, S.; Arciola, C.R. Scenery of staphylococcus implant infections in orthopedics. Future Microbiol. 2011, 6, 1329-1349. [CrossRef] [PubMed]

17. Nethercott, C.; Mabbett, A.N.; Totsika, M.; Peters, P.; Ortiz, J.C.; Nimmo, G.R.; Coombs, G.W.; Walker, M.J.; Schembri, M.A. Molecular characterization of endocarditis-associated Staphylococcus aureus. J. Clin. Microbiol. 2013, 51, 2131-2138. [CrossRef] [PubMed]

18. Cardile, A.P.; Sanchez, C.J., Jr.; Samberg, M.E.; Romano, D.R.; Hardy, S.K.; Wenke, J.C.; Murray, C.K.; Akers, K.S. Human plasma enhances the expression of staphylococcal microbial surface components recognizing adhesive matrix molecules promoting biofilm formation and increases antimicrobial tolerance in vitro. BMC Res. Notes 2014, 7, 457. [CrossRef] [PubMed]

19. Zapotoczna, M.; McCarthy, H.; Rudkin, J.K.; O'Gara, J.P.; O’Neill, E. An essential role for coagulase in Staphylococcus aureus biofilm development reveals new therapeutic possibilities for device-related infections. J. Infect. Dis. 2015, 212, 1883-1893. [CrossRef] [PubMed]

20. Kwiecinski, J.; Peetermans, M.; Liesenborghs, L.; Na, M.; Bjornsdottir, H.; Zhu, X.; Jacobsson, G.; Johansson, B.R.; Geoghegan, J.A.; Foster, T.J.; et al. Staphylokinase control of Staphylococcus aureus biofilm formation and detachment through host plasminogen activation. J. Infect. Dis. 2016, 213, 139-148. [CrossRef] [PubMed]

21. McCourt, J.; O’Halloran, D.P.; McCarthy, H.; O'Gara, J.P.; Geoghegan, J.A. Fibronectin-binding proteins are required for biofilm formation by community-associated methicillin-resistant Staphylococcus aureus strain lac. FEMS Microbiol. Lett. 2014, 353, 157-164. [CrossRef] [PubMed]

22. Cheng, A.G.; DeDent, A.C.; Schneewind, O.; Missiakas, D. A play in four acts: Staphylococcus aureus abscess formation. Trends Microbiol. 2011, 19, 225-232. [CrossRef] [PubMed]

23. Rammelkamp, C.H.; Hezebicks, M.M.; Dingle, J.H. Specific coagulases of Staphylococcus aureus. J. Exp. Med. 1950, 91, 295-307. [CrossRef] [PubMed]

24. Coraca-Huber, D.C.; Fille, M.; Hausdorfer, J.; Pfaller, K.; Nogler, M. Evaluation of MBEC-HTP biofilm model for studies of implant associated infections. J. Orthop. Res. 2012, 30, 1176-1180. [CrossRef] [PubMed] 
25. Molina-Manso, D.; del Prado, G.; Ortiz-Perez, A.; Manrubia-Cobo, M.; Gomez-Barrena, E.; Cordero-Ampuero, J.; Esteban, J. In vitro susceptibility to antibiotics of staphylococci in biofilms isolated from orthopaedic infections. Int. J. Antimicrob. Agents 2013, 41, 521-523. [CrossRef] [PubMed]

26. Girard, L.P.; Ceri, H.; Gibb, A.P.; Olson, M.; Sepandj, F. MIC versus mbec to determine the antibiotic sensitivity of Staphylococcus aureus in peritoneal dialysis peritonitis. Perit. Dial. Int. 2010, 30, 652-656. [CrossRef] [PubMed]

27. LaPlante, K.L.; Mermel, L.A. In vitro activities of telavancin and vancomycin against biofilm-producing Staphylococcus aureus, S. epidermidis, and enterococcus faecalis strains. Antimicrob. Agents Chemother. 2009, 53, 3166-3169. [CrossRef] [PubMed]

28. Singh, R.; Ray, P.; Das, A.; Sharma, M. Penetration of antibiotics through Staphylococcus aureus and Staphylococcus epidermidis biofilms. J. Antimicrob. Chemother. 2010, 65, 1955-1958. [CrossRef] [PubMed]

29. Jefferson, K.K.; Goldmann, D.A.; Pier, G.B. Use of confocal microscopy to analyze the rate of vancomycin penetration through Staphylococcus aureus biofilms. Antimicrob. Agents Chemother. 2005, 49, 2467-2473. [CrossRef] [PubMed]

30. Chaignon, P.; Sadovskaya, I.; Ragunah, C.; Ramasubbu, N.; Kaplan, J.B.; Jabbouri, S. Susceptibility of staphylococcal biofilms to enzymatic treatments depends on their chemical composition. Appl. Microbiol. Biotechnol. 2007, 75, 125-132. [CrossRef] [PubMed]

31. Kaplan, J.B.; LoVetri, K.; Cardona, S.T.; Madhyastha, S.; Sadovskaya, I.; Jabbouri, S.; Izano, E.A. Recombinant human dnase I decreases biofilm and increases antimicrobial susceptibility in staphylococci. J. Antibiot. 2012, 65, 73-77. [CrossRef] [PubMed]

32. Kaplan, J.B. Biofilm matrix-degrading enzymes. Methods Mol. Biol. 2014, 1147, 203-213. [PubMed]

33. Nemoto, K.; Hirota, K.; Ono, T.; Murakami, K.; Murakami, K.; Nagao, D.; Miyake, Y. Effect of varidase (streptokinase) on biofilm formed by Staphylococcus aureus. Chemotherapy 2000, 46, 111-115. [CrossRef] [PubMed]

34. Vanassche, T.; Peetermans, M.; Van Aelst, L.N.; Peetermans, W.E.; Verhaegen, J.; Missiakas, D.M.; Schneewind, O.; Hoylaerts, M.F.; Verhamme, P. The role of staphylothrombin-mediated fibrin deposition in catheter-related Staphylococcus aureus infections. J. Infect. Dis. 2013, 208, 92-100. [CrossRef] [PubMed]

35. Kwiecinski, J.; Na, M.; Jarneborn, A.; Jacobsson, G.; Peetermans, M.; Verhamme, P.; Jin, T. Tissue plasminogen activator coating on implant surfaces reduces Staphylococcus aureus biofilm formation. Appl. Environ. Microbiol. 2016, 82, 394-401. [CrossRef] [PubMed]

36. Ceri, H.; Olson, M.E.; Stremick, C.; Read, R.R.; Morck, D.; Buret, A. The calgary biofilm device: New technology for rapid determination of antibiotic susceptibilities of bacterial biofilms. J. Clin. Microbiol. 1999, 37, 1771-1776. [PubMed]

37. Pietrocola, G.; Nobile, G.; Gianotti, V.; Zapotoczna, M.; Foster, T.J.; Geoghegan, J.A.; Speziale, P. Molecular interactions of human plasminogen with fnbpb, a fibrinogen/fibronectin-binding protein from Staphylococcus aureus. J. Biol. Chem. 2016, 291, 18148-18162. [CrossRef] [PubMed]

38. Salazar, N.; Castiblanco-Valencia, M.M.; da Silva, L.B.; de Castro, I.; Monaris, D.; Masuda, H.P.; Barbosa, A.S.; Areas, A.P. Staphylococcus aureus manganese transport protein c (MNTC) is an extracellular matrix- and plasminogen-binding protein. PLoS ONE 2014, 9, e112730. [CrossRef] [PubMed]

39. Shanks, R.M.; Donegan, N.P.; Graber, M.L.; Buckingham, S.E.; Zegans, M.E.; Cheung, A.L.; O’Toole, G.A. Heparin stimulates Staphylococcus aureus biofilm formation. Infect. Immun. 2005, 73, 4596-4606. [CrossRef] [PubMed]

40. Chauhan, A.; Lebeaux, D.; Ghigo, J.M.; Beloin, C. Full and broad-spectrum in vivo eradication of catheter-associated biofilms using gentamicin-edta antibiotic lock therapy. Antimicrob. Agents Chemother. 2012, 56, 6310-6318. [CrossRef] [PubMed]

41. Estes, R.; Theusch, J.; Beck, A.; Pitrak, D.; Mullane, K.M. Activity of daptomycin with or without 25 percent ethanol compared to combinations of minocycline, edta, and 25 percent ethanol against methicillin-resistant Staphylococcus aureus isolates embedded in biofilm. Antimicrob. Agents Chemother. 2013, 57, 1998-2000. [CrossRef] [PubMed]

42. Bjarnsholt, T.; Alhede, M.; Alhede, M.; Eickhardt-Sorensen, S.R.; Moser, C.; Kuhl, M.; Jensen, P.O.; Hoiby, N. The in vivo biofilm. Trends Microbiol. 2013, 21, 466-474. [CrossRef] [PubMed]

43. McCarthy, H.; Rudkin, J.K.; Black, N.S.; Gallagher, L.; O'Neill, E.; O'Gara, J.P. Methicillin resistance and the biofilm phenotype in Staphylococcus aureus. Front. Cell. Infect. Microbiol. 2015, 5, 1. [CrossRef] [PubMed] 
44. Stein, G.E.; LeBel, M.; Flor, S.C.; Zinny, M. Bioavailability and pharmacokinetics of oral ofloxacin formulations in normal subjects. Curr. Med. Res. Opin. 1991, 12, 479-484. [CrossRef] [PubMed]

45. Benvenuto, M.; Benziger, D.P.; Yankelev, S.; Vigliani, G. Pharmacokinetics and tolerability of daptomycin at doses up to 12 milligrams per kilogram of body weight once daily in healthy volunteers. Antimicrob. Agents Chemother. 2006, 50, 3245-3249. [CrossRef] [PubMed]

46. Rybak, M.J.; Lomaestro, B.M.; Rotschafer, J.C.; Moellering, R.C.; Craig, W.A.; Billeter, M.; Dalovisio, J.R.; Levine, D.P. Vancomycin therapeutic guidelines: A summary of consensus recommendations from the infectious diseases society of america, the american society of health-system pharmacists, and the society of infectious diseases pharmacists. Clin. Infect. Dis. 2009, 49, 325-327. [CrossRef] [PubMed]

47. Alvarez, R.; Lopez Cortes, L.E.; Molina, J.; Cisneros, J.M.; Pachon, J. Optimizing the clinical use of vancomycin. Antimicrob. Agents Chemother. 2016, 60, 2601-2609. [CrossRef] [PubMed]

48. Chirouze, C.; Alla, F.; Fowler, V.G., Jr.; Sexton, D.J.; Corey, G.R.; Chu, V.H.; Wang, A.; Erpelding, M.L.; Durante-Mangoni, E.; Fernandez-Hidalgo, N.; et al. Impact of early valve surgery on outcome of Staphylococcus aureus prosthetic valve infective endocarditis: Analysis in the international collaboration of endocarditis-prospective cohort study. Clin. Infect. Dis. 2015, 60, 741-749. [CrossRef] [PubMed]

49. Prendergast, B.D.; Tornos, P. Surgery for infective endocarditis: Who and when? Circulation 2010, 121, 1141-1152. [CrossRef] [PubMed]

(C) 2016 by the authors; licensee MDPI, Basel, Switzerland. This article is an open access article distributed under the terms and conditions of the Creative Commons Attribution (CC-BY) license (http:/ / creativecommons.org/licenses/by/4.0/). 